\title{
Incidence of retinopathy of prematurity in neonatal intensive care unit in a tertiary care centre in central India
}

\author{
Athale A. ${ }^{\mathbf{1}}$, Jain S. ${ }^{*}$ \\ DOI: https://doi.org/10.17511/jooo.2020.i01.01 \\ ${ }^{1}$ Ashish Athale, Assistant Professor, Department of Ophthalmology, Chirayu medical College and Hospital, Bhopal, Madhya Pradesh, India. \\ 2* Sandeep Jain, Assistant Professor, Department of Ophthalmology, Chirayu medical College and Hospital, Bhopal, Madhya Pradesh, India.
}

Introduction: Retinopathy of Prematurity (ROP) is one of the most common disorders affecting the eyes of premature infants, characterized by abnormal proliferation of retinal blood vessels. In the absence of treatment, it can result in retinal detachment and permanent loss of vision. Advances in neonatal care have resulted in increase in survival rates of very premature infants and consequent increase in incidence of ROP. Purpose: The present study, conducted in a single NICU in a tertiary care centre, estimates the incidence of ROP and evaluates the associated risk factors. Materials and Methods: A retrospective cohort study was performed on premature infants in a tertiary care unit in Central India between February 2018 to July 2019. One hundred and four infants were included in the study based on the following inclusion criteria: Gestational age below 34 weeks, Birth weight below $1700 \mathrm{gms}$, or babies born with gestational age above 34 weeks or birth weight above 1700 gms, but with any of the following: respiratory distress syndrome, sepsis, intraventricular hemorrhage, blood transfusions or multiple gestation. Follow up was done until disease resolution or until treatment criteria were achieved. Results: A total of 104 infants were evaluated after applying the inclusion criteria. Babies that were screened had mean GA of 30.28 weeks (SD: 2.84, range: 26-36 weeks). Babies with ROP had a mean GA of 28.91 weeks (range: 26-36 weeks, SD: 2.64). The mean Birth weight for the cohort was $1468 \mathrm{~g}$ (standard deviation [SD]: 300, range: 830-1870 g). Babies in ROP group had a mean BW of $1278 \mathrm{~g}$ (SD: 0.27, range: $830-1726 \mathrm{~g}$ ). The incidence of ROP of any stage was found to be $25.96 \%$. Babies with a GA of $<28$ weeks had the highest incidence of ROP (62.8\%). A significant association was noted between ROP and oxygen therapy $(P<0.01)$ as well as $\operatorname{RDS}(P<0.02)$. Conclusion: This study found incidence of ROP to be $25.96 \%$ in the target population and showed respiratory distress and Oxygen therapy to be significant risk factors associated with the disease.

Keywords: Aggressive posterior ROP, Laser photocoagulation, Neonatal intensive care unit, Retinopathy of Prematurity

\section{Corresponding Author}

Sandeep Jain, Assistant Professor, Department of Ophthalmology, Chirayu medical College and Hospital, Bhopal, Madhya Pradesh, India. Email: sjain2002@gmail.com

\section{How to Cite this Article}

Athale A, Jain S. Incidence of retinopathy of prematurity in neonatal intensive care unit in a tertiary care centre in central India. Trop J Ophthalmol Otolaryngol. 2020;5(1):1-5. Available From https://opthalmology.medresearch.in/index.php/jooo /article/view/108

\section{To Browse}

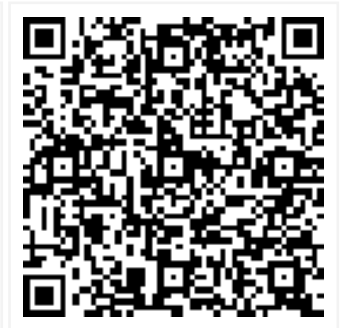

Manuscript Received 2019-12-20

Conflict of Interest No
Review Round 1 2019-12-30
Note 


\section{Introduction}

Retinopathy of prematurity (ROP) is a rapidly increasing cause of avoidable childhood blindness worldwide [1]. It is a vision-threatening disease associated with abnormal retinal vascular development at the boundary of vascularized and avascular peripheral retina [2]. In developed countries, the incidence of ROP seems to be declining over the last few decades. In developing countries, however, high fertility rates and increasing resuscitation of premature infants, often with suboptimal standards of care, have resulted in a third epidemic of ROP [3].

Short gestational age and LBW have been identified as the most important risk factors responsible for ROP, the other recognized risk factors being sepsis, intraventricular hemorrhage (IVH), mechanical ventilation, oxygen therapy, blood transfusion, and exposure to light [4]. Majority of ROP cases are mild and resolve spontaneously without treatment. A small proportion progress to more severe ROP, which, if untreated, can progress to retinal detachment and irreversible vision loss [5].

Recently, there has been observed an increase in the number of preterm babies with ROP in India [6]. This may be the result of high birth rate, high rate of preterm births, and survival of LBW children due to the advanced and expanded provision of medical care [7]. Increased numbers of pediatric ophthalmologists and vitreoretinal surgeons in the country has also led to ROP becoming increasingly recognized [6]. This study was, therefore, planned and initiated to assess the current incidence and severity of ROP in preterm infants and to determine the neonatal and maternal risk factors for the same.

\section{Materials and Methods}

Setting: This study was conducted in Chirayu Medical College and Hospital, a tertiary care Institute at Bhopal, as a prospective, observational study involving babies at risk of ROP. $\mathrm{CMCH}$ is equipped with NICU having advanced facilities for neonatal care and resuscitation.

Duration and type of study: This was a prospective study conducted to assess the incidence of ROP in premature infants and to determine risk factors for its development. Enrolment was for a period of 18 months, from 1st February 2018 to 30th July 2019.
Permissions: Permission was taken from the Ethics Committee of the Institute. Written informed consent was obtained from the parents regarding examination and treatment of their babies, after duly explaining benefits and risks in their native language.

Inclusion criteria: All babies fulfilling the following criteria were included:

01. Gestational age (GA) at birth of $\leq 34$ weeks

02. Birth Weight of $\leq 1700 \mathrm{~g}$

03. Babies with $\mathrm{GA}>34$ weeks and $\mathrm{BW}>1700$ if the treating Paediatrician recommended ROP screening due to stormy perinatal course in NICU

04. Follow-up period of at least 3 months

\section{Exclusion criteria}

01. Incomplete hospital documentation of pre- and perinatal comorbidities and

02. Incomplete follow-up

Procedure: After explaining the benefits and risks, a written informed consent was obtained from the parents regarding examination and treatment. All relevant information including that related to NICU care and risk factors for ROP were duly recorded in a prepared proforma. Risk factors that were assessed were as follows: duration and concentration of oxygen therapy, respiratory distress syndrome (RDS), sepsis, history of blood transfusion, surfactant therapy, multiple gestations, and intra ventricular hemorrhage. From the patient's chart, maternal and neonatal comorbid conditions, if any, were noted and recorded.

Initial screening of all premature infants was done at 4 weeks after delivery. Diluted $0.8 \%$ tropicamide and $5 \%$ phenylephrine eye drops were used to dilate the pupils. Eyes were kept open with the help of eye speculum. A senior retina specialist with experience in ROP examined the babies using indirect ophthalmoscopy and vectis for scleral depression. The findings were recorded in a chart. The international classification of ROP was used to document all retinal examination findings [8].

As per standard schedule for screening, babies were called for further examinations. In the absence of ROP, screening was continued till vascularisation reached zone 3 or completion of 45 weeks post menstrual age, whichever was earlier. Treatment was offered to babies who fulfilled criteria according to ETROP study [9]. 
Data analysis: Statistical analysis was performed using a commercially available statistical software package (STATA, version 11.0, Texas, USA). Univariate comparison of risk factors between eyes with and without ROP was done using Chi-square test and Fisher's exact test. Multivariate analysis was performed with binary logistic regression to compare the incidence of ROP as response variable and various risk factors. A p-value $<0.05$ was considered to indicate a statistically significant association between a risk factor and the risk of developing ROP.

\section{Results}

One hundred and four babies were enrolled for the study, on the basis the inclusion criteria detailed above. There were 60 (57\%) males and 44 (43\%) females. ROP was seen in 52 eyes of 27 babies giving an incidence of $25.96 \%$ with 25 (92.59\%) babies having bilateral disease. Aggressive posterior disease seen in 8 (29.62\%) babies while classic ROP with stage 2 or worse was seen in 13 babies (48.14\%) [Table 1: Incidence of ROP according to stage].

Table 1: Incidence of ROP according to stage.

\begin{tabular}{|l|l|l|}
\hline \multicolumn{1}{|c|}{ Stage of ROP } & Number of eyes & \multicolumn{1}{c|}{ Percent of total } \\
\hline 1 & 8 & 15.38 \\
\hline 2 & 14 & 26.92 \\
\hline 3 & 12 & 23.07 \\
\hline 4 & 2 & 3.84 \\
\hline 5 & 2 & 3.84 \\
\hline APROP & 14 & 26.92 \\
\hline
\end{tabular}

The mean Birth weight for the cohort was $1468 \mathrm{~g}$ (standard deviation [SD]: 300, range: 830-1870 g). Babies in ROP group had a mean BW of $1278 \mathrm{~g}$ (SD: 0.27 , range: $830-1726 \mathrm{~g}$ ) while the mean for babies without ROP was $1452 \mathrm{~g}$ (range: 850 -1870 g, SD: 0.24). This difference was statistically significant with $P<0.001$. The incidence of ROP was inversely related to BW with babies weighing $<1000$ $\mathrm{g}$ having the highest incidence of $71.78 \%$.

Table-2: Relationship between birth weight and retinopathy of prematurity.

\begin{tabular}{|l|l|l|l|}
\hline \multicolumn{1}{|c|}{ Birth weight $(\mathrm{Kg})$} & \multicolumn{1}{c|}{ ROP present } & \multicolumn{1}{c|}{ ROP absent } & \multicolumn{1}{c|}{ Total } \\
\hline$<1$ & $9(33.33 \%)$ & $5(7.35 \%)$ & 14 \\
\hline $1.01-1.25$ & $11(40.74 \%)$ & $14(20.58 \%)$ & 25 \\
\hline $1.26-1.5$ & $10(37.03 \%)$ & $26(38.23 \%)$ & 36 \\
\hline $1.51-1.75$ & $5(18.51 \%)$ & $16(23.52 \%)$ & 21 \\
\hline $1.76-1.9$ & $1(3.70 \%)$ & $7(10.29 \%)$ & 8 \\
\hline Total & $27(100 \%)$ & $68(100 \%)$ & 104 \\
\hline
\end{tabular}

Babies that were screened had mean GA of 30.28 weeks (SD: 2.84, range: 26-36 weeks). Babies with ROP had a mean GA of 28.91 weeks (range: 26-36 weeks, SD: 2.64) while mean GA for babies without ROP was 31.14 weeks (range: 26-36 weeks, SD: 2.80). This difference was statistically significant $(P<0.001)$. Babies with a GA of $<28$ weeks had the highest incidence of ROP (62.8\%). Seventeen (63\%) out of 27 babies with ROP and 51 (66\%) out of 77 babies without ROP had mothers $\leq 25$ years of age. This difference was not statistically significant with $\mathrm{P}=0.13$.

Table 3 shows the association between ROP and other risk factors. A significant association was noted between ROP and oxygen therapy as well as RDS. No significant association was noted between occurrence of ROP and remaining risk factors including IVH, blood transfusion, sepsis, multiple gestations, gestational diabetes and maternal hypertension. On multiple logistic regression analysis, only LBW remained a statistically significant and independent risk factor for ROP (Table 3).

Table 3: Association between ROP and other risk factors.

\begin{tabular}{|l|l|l|l|}
\hline & No ROP & ROP & P \\
\hline Oxygen therapy & 4 & 13 & 0.01 \\
\hline Blood transfusion & 4 & 5 & 0.06 \\
\hline Sepsis & 3 & 2 & 0.22 \\
\hline Intra ventricular hemorrhage & 1 & 1 & 0.35 \\
\hline Respiratory distress syndrome & 10 & 9 & 0.02 \\
\hline Gestational Diabetes & 5 & 6 & 0.14 \\
\hline Maternal hypertension & 5 & 2 & 0.35 \\
\hline
\end{tabular}

18 eyes of 10 babies (37.03\%) were administered treatment for ROP. Laser photocoagulation, intravitreal antivascular endothelial growth factor injection, and surgery comprised the three modes of treatment. Laser treatment was done in all 10 babies with 2 babies receiving unilateral treatment while 8 were treated in both eyes. All treated babies were followed up till regression of ROP occurred in all the eyes. One baby with unilateral stage 4B ROP underwent lens sparing vitrectomy, and 1 baby with bilateral closed funnel total retinal detachment did not have any surgical intervention. All babies with initial presentation of stage 1 ROP regressed without treatment.

\section{Discussion}

ROP is one of the major causes of vision loss in premature infants in India. 
The incidence is increasing with improvement in survival rates of infants delivered at very low gestational ages [10]. The incidence of ROP in this study was $25.96 \%$ which corresponds to that found in previous studies in India (15.6\%-47.3\%) [1115]. Major risk factors for ROP are prematurity, Low birth weight, oxygen therapy, RDS, sepsis and blood transfusion [16]. Of these LBW, low GA and oxygen therapy are considered the most important risk factors for ROP with LBW being the greatest predictor of severity $[16,17]$. The incidence and severity of ROP show an inverse relationship with BW and GA, with few cases diagnosed in babies weighing over $1500 \mathrm{~g}$ or babies whose GA is >32 weeks at birth. Few reports indicate risk of ROP in mature babies as well $[14,18-22]$.

Indian babies have been found to have early onset and more rapid progression of the disease than their counterparts from other countries [21]. Twenty one percent of babies with ROP in this present study weighed $>1500 \mathrm{~g}$ which is much lower than $65 \%$ reported by Hungi et al [18]. ROP babies had mean birth weight of $1278 \mathrm{~g}$ in this study, which compares favorably with the study by Charan et al [15] but other studies in India have reported it to be higher than this.

Logistic regression analysis did not show low GA to be a significant risk factor in this present study. This compares favorably with study by Chaudhari et al [13] but is in contrast with finding by Murthy et al [12]. A mean GA of 28.91 weeks for ROP babies in this series was obtained, while previous reports showed range from 30.8 to 32 weeks, so this is lower $[11,12,14,15,18]$. The lower gestational age, lower birth weight, as well as the lower proportion of babies weighing $>1500 \mathrm{~g}$ with ROP in this series reflect significantly improved in standards of neonatal care.

Treatment for ROP was carried out in 10 (37.03\%) babies in this series. This falls towards the lower end of the range of $26 \%-75 \%$ reported in previous studies $[11,12,13,18]$. This shows that the incidence of severe ROP maybe declining. This may be related to improvements in neonatal care and monitoring of oxygen therapy in the NICUs. It is possible though that this observed decline in severe ROP may not necessarily be applicable to other hospitals in the area. Studies have demonstrated that with changes in neonatal care such as use of pulse oximeters, target based approach for maintenance of oxygen saturation and education of staff, the rates of treatable ROP can be reduced [23-25].
Limitations: Small sample size is a limitation of the present study. The hospital is located in an urban area, is better equipped and therefore may have shown lower incidence of severe ROP compared with NICUs in rural areas.

\section{Conclusions}

To conclude, the incidence of ROP was $25.96 \%$ in the present study. It was strongly associated with LBW. Babies with ROP were found to have lower mean GA and BW, compared with previous Indian studies. A reduction in the severe forms of the disease along with the above are evidences of improving standards of neonatal care.

An improvement in access to Ophthalmic care with better screening protocols, are desirable along with sustainability in standards of neonatal care delivery, to reduce the incidence of this preventable cause of childhood blindness.

\section{What this study adds to existing knowledge}

This study reports incidence of ROP in a tertiary centre in central India, while previous studies have been conducted in North and South India. The incidence of severe and treatable ROP was found to be lower as compared to previous studies which may point towards improving standards of neonatal care, and hence the need to expand the same to cover rural areas.

\section{Author's contribution}

The screening and follow up of infants were done jointly by Dr. Ashish Athale and Dr. Sandeep Jain.

Data analysis with statistician was done by Dr. Sandeep.

Manuscript preparation was done by Dr. Ashish.

\section{Reference}

01. Blencowe $\mathrm{H}$, Lawn JE, Vazquez $T$, Fielder $A$, Gilbert C. Preterm-associated visual impairment and estimates of retinopathy of prematurity at regional and global levels for 2010. Pediatr Res. 2013;74(1)35-49. doi: 10.1038\%2Fpr.2013.205 [Crossref][PubMed][Google Scholar] 
02. Good WV, Hardy RJ, Dobson V, Palmer EA, Phelps DL, Quintos $M$, et al. The incidence and course of retinopathy of prematurity- Findings from the early treatment for retinopathy of prematurity study. Pediatrics. 2005;116(1)15-23. doi: 10.1542/peds.2004-1413 [Crossref][PubMed] [Google Scholar]

03. Zin A, Gole GA. Retinopathy of prematurityincidence today. Clin Perinatol. 2013;40(2)185-200. doi: 10.1016/j.clp.2013.02.001 [Crossref][PubMed] [Google Scholar]

04. Karna P, Muttineni J, Angell L, Karmaus W. Retinopathy of prematurity and risk factors- A prospective cohort study. BMC Pediatr. 2005;5(1)18. doi: 10.1186/1471-2431-5-18 [Crossref][PubMed] [Google Scholar]

05. Palmer EA, Flynn JT, Hardy RJ, Phelps DL, Phillips $C L$, Schaffer $D B$, et al. Incidence and early course of retinopathy of prematurity, The cryotherapy for retinopathy of prematurity cooperative group. Ophthalmol. 1991;98(11)16281640. doi: 10.1016/s0161-6420(91)32074-8 [Crossref][PubMed][Google Scholar]

06. Azad R. Prevention of blindness due to retinopathy of prematurity- A national movement. Indian J Pediatr. 2014;81(12)1373-1375. doi: 10.1007/s12098-014-1411-x [Crossref][PubMed] [Google Scholar]

07. Puri S, Sarpal S, Ashat M. Screening of retinopathy of prematurity- $A$ neglected public health issue. Ann Med Health Sci Res. 2014;4(1)S65-S66. doi: 10.4103\%2F21419248.131726 [Crossref][PubMed][Google Scholar]

08. International Committee for the Classification of Retinopathy of Prematurity. The international classification of retinopathy of prematurity revisited. Arch Ophthalmol. 2005;123(7)991-999. doi: 10.1001/archopht.123.7.991 [Crossref][PubMed] [Google Scholar]

09. Section on Ophthalmology, American Academy of Pediatrics. American Academy of Ophthalmologists, American Association for Pediatric Ophthalmology and Strabismus. Screening examinations for premature infants for retinopathy of prematurity. Pediatri. 2006;117(2)572-576. doi: 10.1542/peds.2005-2749 [Crossref][PubMed]
10. Chen J, Stahl A, Hellstrom A, Smith LE. Current update on retinopathy of prematurity- Screening and treatment. Curr Opin Pediatr. 2011;23(2)173178. doi: 10.1097/MOP.0b013e3283423f35 [Crossref][PubMed][Google Scholar]

11. Murthy KR, Murthy PR, Shah DA, Nandan MR, Niranjan HS, Benakappa N. Comparison of profile of retinopathy of prematurity in semiurban/rural and urban NICUs in Karnataka, India. $\mathrm{Br} \mathrm{J}$ Ophthalmol. 2013;97(6)687-689. doi: 10.1136/bjophthalmol2012-302801 [Crossref][PubMed][Google Scholar]

12. Murthy KR, Babu K, Benakappa N, Murthy PR, Nagendra Niranjan. Analysis of risk factors for the development of retinopathy of prematurity in preterm infants at a tertiary referral hospital in South India. Acta Med Litu. 2006;13(3)147-151. [Crossref][PubMed][Google Scholar]

13. Chaudhari S, Patwardhan V, Vaidya U, Kadam S, Kamat A. Retinopathy of prematurity in a tertiary care center - Incidence, risk factors and outcome. Indian Pediatr. 2009;46(3)219-224. [Crossref] [PubMed][Google Scholar]

14. Ashok KM, Rajalakshmi AR, Gunasekaran D, Sreeraaganidhi. A study of risk factors for retinopathy of prematurity in a medical college hospital in South India to evaluate the criteria for screening for retinopathy of prematurity. J Curr Trends Clin Med Lab Biochem. 2014;2(2)31-36. [Crossref][PubMed][Google Scholar]

15. Charan R, Dogra MR, Gupta A, Narang A. Incidence of retinopathy of prematurity in $a$ neonatal care unit. Indian J Ophthalmol. 1995;43(3)123-126. [Crossref][PubMed][Google Scholar]

16. Fortes Filho JB, Eckert GU, Valiatti FB, Dos Santos PG, da Costa MC, Procianoy RS, et al. The influence of gestational age on the dynamic behavior of other risk factors associated with retinopathy of prematurity (ROP). Graefes Arch Clin Exp Ophthalmol. 2010;248(6)893-900. doi: 10.1007\%2Fs00417-009-1248-6 [Crossref] [PubMed][Google Scholar]

17. McColm JR, Fleck BW. Retinopathy of prematurity- Causation. Semin Neonatol. 2001;6(6)453-460. Doi: 10.1053/siny.2001.0079 [Crossref][PubMed][Google Scholar]

[Google Scholar] 
18. Hungi B, Vinekar A, Datti N, Kariyappa $P$, Braganza S, Chinnaiah $S$, et al. Retinopathy of prematurity in a rural Neonatal Intensive Care Unit in South India - A prospective study. Indian J Pediatr. 2012;79(7)911-915. doi: 10.1007/s12098012-0707-y [Crossref][PubMed][Google Scholar]

19. Fortes Filho JB, Eckert GU, Procianoy L, Barros CK, Procianoy RS. Incidence and risk factors for retinopathy of prematurity in very low and in extremely low birth weight infants in a unit-based approach in Southern Brazil. Eye (Lond). 2009;23(1)25-30. doi: 10.1038/sj.eye.6702924 [Crossref][PubMed][Google Scholar]

20. Kapoor R, Talwar R, Sachdeva S, Paul P, Yadav $\mathrm{R}$, Sachdeva $\mathrm{S}$. Retinopathy of prematurity in babies weighing $<1800 \mathrm{~g}$; with special reference to babies weighing between 1501 and $1800 \mathrm{~g}$ - An experience from a tertiary care hospital in Delhi. Int J Med Public Health. 2014;4(4)359-363. doi: 10.4103/2230-8598.144066 [Crossref][PubMed] [Google Scholar]

21. Shah PK, Narendran V, Kalpana N, Gilbert C. Severe retinopathy of prematurity in big babies in India- History repeating itself?. Indian J Pediatr. 2009;76(8)801-804. doi: 10.1007/s12098-0090175-1 [Crossref][PubMed][Google Scholar]
22. Jalali S, Matalia J, Hussain A, Anand R. Modification of screening criteria for retinopathy of prematurity in India and other middle-income countries. Am J Ophthalmol. 2006;141(5)966-968. doi: 10.1016/j.ajo.2005.12.016 [Crossref][PubMed] [Google Scholar]

23. Wu WC, Ong FS, Kuo JZ, Lai CC, Wang NC, Chen $\mathrm{KJ}$, et al. Retinopathy of prematurity and maternal age. Retina. 2010;30(2)327-331. doi: 10.1097/IAE.0b013e3181ba246f [Crossref] [PubMed][Google Scholar]

24. Uchida A, Miwa M, Shinoda H, Koto T, Nagai N, Mochimaru $H$, et al. Association of maternal age to development and progression of retinopathy of prematurity in infants of gestational age under 33 weeks. J Ophthalmol. 2014;187929. doi: 10.1155/2014/187929 [Crossref][PubMed][Google Scholar]

25. Bizzarro MJ, Li FY, Katz K, Shabanova V, Ehrenkranz RA, Bhandari $V$, et al. Temporal quantification of oxygen saturation ranges- An effort to reduce hyperoxia in the Neonatal Intensive Care Unit. J Perinatol. 2014;34(1)33-38. doi: 10.1038/jp.2013.122 [Crossref][PubMed][Google Scholar] 